\title{
ASPECTOS CONSTITUCIONALES DE LA DEFENSA JURÍDICA CONTRA EL FENÓMENO DEL RUIDO
}

POR

LUIS VACAS GARCÍA-ALÓS

Magistrado de lo Contencioso-Administrativo, Letrado del CGPJ

Profesor Asociado de Derecho Constitucional de la UNED

\section{LA CONSTITUCIONALIZACIÓN DE LA DEFENSA CONTRA LA CONTAMINACIÓN AMBIENTAL}

\subsection{La tutela jur dica del medio ambiente}

En términos jurídico-constitucionales, la defensa contra la contaminación ambiental abarca un doble ámbito de consideración: en primer lugar, el artículo 45 de la Constitución (CE), que constitucionaliza el derecho a disfrutar de un medio ambiente adecuado para el desarrollo de la persona $y$, al mismo tiempo, el deber de conservarlo; $y$, en segundo término, el encuadramiento sistemático de dicho precepto constitucional en el capítulo III del Título I de la CE, del que inequívocamente se infiere la obligación de rango constitucional de acción inherente al Estado social y democrático de Derecho, conforme a las previsiones establecidas en los artículos $1^{\circ} .1$ y 10.1 de la propia CE.

El medio ambiente así configurado, y la consiguiente responsabilidad constitucional acerca de su debida conservación, se encuentra expre- 
samente unido al desarrollo de la persona y a la calidad de vida. Con arreglo a este planteamiento es de destacar, en palabras de PAREJO ALFONSO, que la mencionada responsabilidad constitucional "tiene su centro de gravedad en la ejecución y, más concretamente, en la ejecución administrativa, en tanto que aparece establecida desde la pretensión de efectividad del medio ambiente requerido para el desarrollo de la persona y la calidad de vida; pretensión que, siendo absoluta y no meramente condicional, comporta la exigencia de eficacia real (y no meramente jurídica), es decir, la que aparece consagrada en el artículo 103.1 CE como principio justamente de la actuación administrativa, en cuanto actuación estatal dirigida a hacer "efectiva» la pertinente programación normativa». La protección ambiental está, pues, dirigida a todos los poderes públicos, sin excepciones, de suerte que su deber de conservación, por razones de interés general, afecta por entero a sus tres principales ámbitos de actuación: la legislación, la ejecución —que, como se ha visto, viene a ser su centro de gravedad-, y, en los supuestos de conflicto, la jurisdicción.

Por consiguiente, la tutela jurídica del ambiente es una función que, predominantemente, está atribuida por el legislador a la Administración. Como señala GONZÁLEZ-VARAS, «de una rápida lectura de los distintos preceptos que integran la protección del ambiente (Ley de contaminación atmosférica, las Leyes de propiedades especiales —aguas, por ejemplo-, el propio Reglamento de actividades) tienen aquéllos un carácter esencialmente objetivo, en el sentido de que declaran facultades o títulos de intervención o incluso obligaciones, cuyo destinatario es la Administración, para que ésta proteja el ambiente». La protección medioambiental es así, en consecuencia, una función netamente administrativa, en la que la Administración Local cuenta con un papel de especial preponderancia.

Siendo, como es, el artículo 45 de la CE un precepto de contenido complejo, resulta claro que la protección jurídica del medio ambiente se articula tanto en una perspectiva estática y objetiva, como en la misma naturaleza jurídica del bien objeto de protección: un concepto jurídico indeterminado y de carácter interdisciplinar, que afecta al Derecho público y al privado —con diferente extensión, pero con plena eficacia jurídica-, y cuya descripción, según la sentencia del Tribunal Constitucional (TC) 102/1995, de 26 de junio, comprende los recursos naturales —el vegetal o la flora y el animal o la fauna en el entorno del espacio natural-y los recursos históricos y culturales - los testimonios o monumentos y el paisaje en toda su extensión-.

Sobre la base de las precedentes consideraciones, se impone, desde nuestro punto de vista, la concepción de la integridad y la efectividad del medio ambiente, así como la ulterior utilización racional de los recursos naturales, como presupuesto y condición de efectividad de los derechos 
constitucionales que demandan de las Administraciones Públicas actuaciones concretas y prestaciones específicas. Esto explica que, como propugna PAREJO ALFONSO, "a través del deber estatal de acción y de resultado, los contenidos principales del Capítulo III del Título I CE y, concretamente, el medio ambiente adecuado se "subjetivizan" en la medida en que los derechos proclamados con motivo del establecimiento de aquéllos y, en particular, el derecho a disfrutar de un medio ambiente adecuado son parte del contenido constitucionalmente declarado de los derechos constitucionales, incluso de los fundamentales-libertades públicas de la sección 1a del Capítulo II del mismo Título I CE».

Puede sostenerse así que el derecho a disfrutar de un medio adecuado constituye un auténtico derecho subjetivo en la medida en que ciertamente se encuentra conectado con derechos fundamentales garantizados en los artículos 15 y 18 de la CE, como los derechos a la integridad física y moral, y a la intimidad personal y familiar en el ámbito domiciliario. Y se da la circunstancia, ciertamente relevante a los efectos de este trabajo, que el anterior posicionamiento se ha consolidado progresivamente en los últimos años. Prueba de ello son las sentencias del Tribunal Europeo de Derechos Humanos (TEDH) de fechas 9 de octubre de 1979, 21 de febrero de 1990, 9 de diciembre de 1994, 19 de febrero de 1998 y 2 de octubre de 2001. Y, en esta misma línea de argumentación, debe destacarse la sentencia de nuestro TC 119/2001, de 24 de mayo, que conoció de un recurso de amparo promovido contra la resolución desestimatoria del contenciosoadministrativo interpuesto frente a la desestimación presunta por un Ayuntamiento de la reclamación de responsabilidad patrimonial por daños causados a consecuencia de la contaminación acústica ocasionada por establecimientos molestos. Dicha sentencia refleja que los citados derechos fundamentales a la integridad física y moral y a la intimidad personal y familiar "han adquirido también una dimensión positiva en relación con el libre desarrollo de la personalidad, orientada a la plena efectividad de estos derechos fundamentales. En efecto — señala la referida sentencia-, habida cuenta de que nuestro texto constitucional no consagra derechos meramente teóricos o ilusorios, sino reales y efectivos (STC 12/1994, de 17 de enero) se hace imprescindible asegurar su protección no sólo frente a las injerencias ya mencionadas, sino también frente a los riesgos que puedan surgir en una sociedad tecnológicamente avanzada».

Y en la protección activa del ambiente adquieren especial relevancia tanto la erradicación de las inmisiones perturbadoras del medio ambiental, como la protección efectiva de los sujetos que sufren inmisiones ilegales. El Ilamado "Derecho público de las inmisiones», del que pasamos a ocuparnos seguidamente, deviene así fundamental en la regulación del particular de referencia. 
1.2. El derecho a la intimidad domiciliaria y la regulaci $n$ jur dica d inmisiones

El Derecho público de las inmisiones tiene gran importancia en el ámbito del Derecho Constitucional, especialmente en el particular relativo a la protección de los derechos fundamentales, y en el campo del Derecho Administrativo, particularmente en la esfera del Derecho Local. Constituye una parcela jurídica esencial de la protección del ambiente, que se articula por medio de un conjunto de normas jurídicas tendentes a erradicar las inmisiones perturbadoras $y$, al mismo tiempo, a regular los mecanismos de defensa por parte de quienes padecen inmisiones ilegales.

En cuanto a los orígenes del concepto jurídico de inmisión, ya hemos señalado en alguna ocasión, siguiendo a FERNÁNDEZ URZAINQUI, que algunos de sus antecedentes remotos pueden encontrarse en el Digesto $(8,5,8,5)$, que alude a la respuesta de Aristón en cuya virtud "solamente le es lícito a uno hacer alguna cosa en su propiedad en tanto no se entrometa en lo ajeno". Y entre los antecedentes más próximos, como apunta el indicado autor, se encuentran los procedentes de la doctrina científica alemana de finales del siglo XIX y de principios del siglo XX. Así, "las primeras aportaciones a la teroría de la immissiorefirieron el concepto únicamente a la introducción en propiedad ajena de sustancias corpóreas o corporales, con lo que venía a negar el carácter de inmisión y la tutela jurídico-civil concebida para ella a la injerencia de elementos carentes de aqueIla sustancialidad como los ruidos y las vibraciones, que podían perturbar los sentidos y afectar a las personas, pero no dañaban la propiedad».

Posteriormente, se ha ido admitiendo de manera progresiva la existencia de inmisiones incorpóreas, no cuestionándose en la actualidad ni en el ámbito de la tutela jurídico-civil de propiedades y de personas, ni mucho menos en el terreno del Derecho público de las inmisiones $y$, en particular, en la esfera de la tutela jurídico-administrativa frente a supuestos casos de inactividad de la Administración. Es más, de un tiempo a esta parte se ha visto considerablemente reforzada la incidencia directa de las inmisiones -especialmente, las inmisiones acústicas o ruidosas- en derechos como la dignidad de la persona, la intimidad personal y familiar, la inviolabilidad del domicilio e, incluso, el derecho a la salud.

La inmisión es, pues, toda injerencia, invasión o interferencia en la esfera jurídica ajena por medio de la realización de actividades molestas, insalubres y nocivas, o a través de la propagación de actos perturbadores de cualquier género, que repercuten negativamente en el conjunto de derechos de los particulares afectados por esos actos o actividades, con una cierta reiteración y por encima del nivel de tolerancia generalmente aceptado en términos de lo que viene a ser una relación normal de vecindad. 
Y es precisamente en el seno del Derecho público de las inmisiones en el que adquiere especial relevancia el que se ha venido en denominar "derecho a la intimidad domiciliaria». Así, tanto de las sentencias del TEDH de 9 de diciembre de 1994 y 19 de febrero de 1998, como de las del TC español 22/1984, de 17 de febrero, 137/1985, de 17 de octubre, 94/1999, de 31 de mayo, y 119/2001, de 24 de mayo, se desprende que, en determinados casos de especial gravedad, ciertos daños ambientales, aun cuando no pongan necesariamente en peligro la salud de las personas, sí pueden atentar contra su derecho al respeto de su vida privada y familiar, con una evidente privación del disfrute de su domicilio, conforme a las previsiones contenidas en el artículo 8.1 del Convenio de Roma.

En este sentido, resulta elocuente el fundamento jurídico sexto de la aludida sentencia del TC, de fecha 24 de mayo de 2001, en el que puede leerse lo siguiente:

«... Respecto a los derechos del art. $18 \mathrm{CE}$, debemos poner de manifiesto que en tanto el art. 8.1 CEDH reconoce el derecho de toda persona "al respeto de su vida privada y familiar, de su domicilio y de su correspondencia», el art. 18 CE dota de entidad propia y diferenciada a los derechos fundamentales a la intimidad personal y familiar (art. 18.1) y a la inviolabilidad del domicilio (art. 18.2). Respecto del primero de estos derechos fundamentales ya hemos advertido en el anterior fundamento jurídico que este Tribunal ha precisado que su objeto hace referencia a un ámbito de la vida de las personas excluido tanto del conocimiento ajeno como de las intromisiones de terceros, y que la delimitación de este ámbito ha de hacerse en función del libre desarrollo de la personalidad. De acuerdo con este criterio hemos de convenir en que uno de dichos ámbitos es el domiciliario por ser aquél en el que los individuos, libres de toda sujeción a los usos y convenciones sociales, ejercen su libertad más íntima ... Teniendo esto presente, podemos concluir que una exposición prolongada a unos determinados niveles de ruido, que puedan objetivamente calificarse como evitables e insoportables, ha de merecer la protección dispensada al derecho fundamental a la intimidad personal y familiar, en el ámbito domiciliario, en la medida en que impidan o dificulten gravemente el libre desarrollo de la personalidad, siempre y cuando la lesión o menoscabo provenga de actos u omisiones de entes públicos a los que sea imputable la lesión producida».

De este modo, el derecho a la intimidad domiciliaria, como variante jurídica que es del derecho a la intimidad personal y familiar en el concreto ámbito domiciliario, queda plenamente reforzado en el conjunto normativo del Derecho público de las inmisiones. $Y$ es de significar, a este respecto, que el mencionado refuerzo abarca un triple ámbito de consideración: en primer lugar, desde el punto de vista objetivo, como mecanismo jurídico para erradicar las inmisiones perturbadoras; en segundo término, 
desde el punto de vista subjetivo, como instrumento activo de defensa por parte de quienes sufren inmisiones ilegales en esa específica parcela domiciliaria; y, por último, desde el punto de vista formal, como técnica procedimental para hacer efectivos los apuntados mecanismos de defensa por parte de quienes padecen esas inmisiones ilegales.

Se ha identificado así, según advierte TARDÓN OLMOS, "como domicilio inviolable el espacio en el cual el individuo vive sin estar sujeto necesariamente a los usos y convenciones sociales y donde ejerce su libertad más íntima (STC 171/1999, de 27 de septiembre). Consecuentemente el objeto específico de protección en este derecho fundamental es tanto el espacio físico, en sí mismo, como también lo que en él hay de emanación de la persona que lo habita (STC 22/1989, de 17 de febrero)".

Así pues, el Derecho público de las inmisiones no puede en modo alguno desconocer la existencia de lo que, a nuestro modo de ver, constituye un inequívoco derecho fundamental: el ya comentado de la intimidad domiciliaria. De aquí que deba admitirse, solventando concepciones doctrinales cada vez más superadas, la existencia de una verdadera tutela jurídica frente a las inmisiones ruidosas, enlazándola así directamente con un derecho fundamental.

Como tendremos ocasión de comentar en el presente trabajo, existe sobrada base doctrinal y jurisprudencial - ya hemos reseñado algunas aportaciones al respecto- para defender la tesis expuesta, ciertamente novedosa desde no hace mucho tiempo, si bien, y como recuerda MARíN CASTÁN, es de justicia reconocer dos destacadas y pioneras opiniones: la de FERNÁNDEZ ASIAÍN, que en 1953 aludía al derecho al silencio como uno de los comprendidos en el derecho a la integridad de la persona, encuadrable en el respeto al "área vital de la persona humana»; y la de MARTÍN-RETORTILLO, que al menos desde 1987 ha venido propugnando un tratamiento del fenómeno del ruido desde la perspectiva de los principios constitucionales y de la protección de los derechos fundamentales.

\section{IMPLICACIONES CONSTITUCIONALES DE LA INACTIVIDAD DE LA ADMINISTRACIÓN EN MATERIA DE DEFENSA CONTRA LA CONTAMINACIÓN AMBIENTAL}

\subsection{El art culo 106.1 de la Constituci n y la Ley de la Jurisdicci $n$ Contencioso-Administrativa de 1998}

Señala el artículo 106.1 de la CE que «los Tribunales controlan la potestad reglamentaria y la legalidad de la actuación administrativa, así 
como el sometimiento de ésta a los fines que la justifican». Y desde esta premisa constitucional surge la importante cuestión de determinar cuáles son las diferentes implicaciones constitucionales de la denominada «inactividad de la Administración", a los concretos efectos de su control jurisdiccional, en un aspecto tan importante en la práctica como es el de la protección jurídica contra la contaminación ambiental.

Es sabido que los preámbulos y las exposiciones de motivos de los textos legales, aunque no tienen valor normativo en sentido estricto, sí constituyen un importante elemento interpretativo a tener en cuenta. De aquí que, a los efectos de precisar el verdadero alcance de la inactividad de la Administración con respecto a la temática de nuestro estudio, deba puntualizarse que la Exposición de Motivos de la Ley 29/1998, de 13 de julio, reguladora de la Jurisdicción Contencioso-Administrativa (LJCA), se expresa en los siguientes términos:

«En el caso del recurso contra la inactividad de la Administración, la Ley establece una reclamación previa en sede administrativa; en el recurso contra la vía de hecho, un requerimiento previo de carácter potestativo, asimismo en sede administrativa. Pero eso no convierte a estos recursos en procesos contra la desestimación, en su caso por silencio, de tales reclamaciones o requerimientos. $\mathrm{Ni}$, como se ha dicho, estas nuevas acciones se atienen al tradicional carácter revisor del recurso contencioso-administrativo, ni puede considerarse que la falta de estimación, total o parcial, de la reclamación o el requerimiento constituyan auténticos actos administrativos, expresos o presuntos. Lo que se persigue es sencillamente dar a la Administración la oportunidad de resolver el conflicto y de evitar la intervención judicial. En caso contrario, lo que se impugna sin más trámites es, directamente, la inactividad o actuación material correspondiente, cuyas circunstancias delimitan el objeto material del proceso".

En esta materia, pues, el legislador supera la clásica concepción revisora del contencioso-administrativo, que aparece así no sólo como mero proceso al acto - que indudablemente lo es-, sino, ante todo, como instrumento formal garantizador de los derechos fundamentales. Son elocuentes, en este orden de consideraciones, los artículos 29 y 32.1 de la citada LJCA, al disponer que cuando la impugnación contencioso-administrativa se dirija contra la inactividad de la Administración, el demandante podrá pretender del órgano jurisdiccional que se condene a la Administración demandada al cumplimiento de sus obligaciones, en los términos legal y reglamentariamente determinados.

En atención a las consideraciones precedentes, no ofrece duda que la protección preventiva del medio ambiente, en general, y de la contaminación ambiental, en particular, pueden articularse en la práctica por medio 
de la apuntada técnica procesal del control jurisdiccional de la inactividad administrativa. Debe ponerse de relieve, no obstante, que dicho control jurisdiccional sólo sería viable cuando se esté en presencia de obligaciones establecidas en normas de origen legal o reglamentario que no precisen actos de aplicación, o en actos administrativos, contratos o convenios, y que consistan en la realización de una concreta prestación a favor de una o varias personas determinadas.

\subsection{El control jurisdiccional de la inactividad administrativa}

Como razona GARCÍA BERNALDO DE QUIRÓS, «en la materia medioambiental, los titulares de dicho derecho (derecho a la intimidad frente a intromisiones de naturaleza medioambiental - contaminación acústica, por ejemplo-) pueden acudir a la vía jurisdiccional fijada en el art. 29.1 de la Ley 29/1998. Dependiendo el éxito de la pretensión del grado de concreción de la actividad administrativa exigida, puesto que de existir tienen singularizada, individualizada o patrimonializada su recepción, por el mero hecho de ser titulares de derechos afectados por la falta de protección del medioambiente».

Consecuentemente, la Adminstración puede y debe actuar en materia de defensa y protección medioambiental; $y$ ante la inactividad administrativa sobre este particular, el ciudadano o ciudadanos directamente afectados por supuestos de contaminación ambiental habrán de acudir a la Jurisdicción Contencioso-Administrativa en demanda de sus concretas pretensiones. Dichas pretensiones, en su caso, podrán dar lugar a la ulterior declaración jurisdiccional de determinadas obligaciones, tendentes, en ese caso, a adoptar las medidas pertinentes relativas a la finalización de la correspondiente actividad, así como, en otro caso, a revocar previas autorizaciones administrativas y a clausurar o suspender actividades.

Lo anteriormente dicho no implica en modo alguno que la fiscalización jurisdiccional sustituya a la actividad administrativa en el ejercicio de potestades propias de la Administración. Así lo especifica el dictamen del Consejo de Estado emitido en 1997 a propósito de la tramitación del Anteproyecto de LJCA, en el que se puntualiza lo que sigue:

"Al regular las pretensiones de condena de la Administración en los supuestos de inactividad material y de vía de hecho, el artículo 31 (32 en la redacción definitiva del articulado) presenta —respecto de la redacción del Anteproyecto de 1995- un inciso añadido al final del apartado 1. Así, el demandante podrá pretender del órgano jurisdiccional que secondene a la Administración al cumplimiento de sus obligaciones en sus concretos tér- 
minos en que estén establecidas "o, en su caso, a dictar el correspondiente adcto administrativo". Sin embargo, estando ante el supuesto de inactividad material de la Administración pública al que se refiere el artículo 28 (actualmente, artículo 29) —como expresamente dice el artículo 31.1 (32.1 del texto finalmente aprobado) - la Administración, en puridad y si se mantiene la radical separación entre actividad formal y material de la Administración que el Anteproyecto pretende, sólo podrá ser condenada a realizar una prestación (que está concretada en virtud de una disposición general que no precisa actos de aplicación, o en virtud de un acto, contrato o convenio administrativo) y no propiamente a dictar un acto administrativo. Además, si tuviera que dictar un acto administrativo de contenido no predeterminado, los Tribunales no deberían sustituir a la Administración en el ejercicio de potestades propias de ésta".

Por tanto, el control jurisdiccional de la inactividad administrativa deviene así fundamental en la defensa contra la contaminación del medio ambiente, en general, y en la protección contra la contaminación acústica, ruidosa o sonora, en particular. Y desde el anterior planteamiento es claro, a nuestro modo de ver, que la inactividad de la Administración sobre el particular de referencia debe ser también objeto de control jurisdiccional en los mismos términos que se establecen en el artículo 106.1 de la CE y con idénticos efectos jurídico-constitucionales que se regulan con respecto a la actividad administrativa propiamente dicha.

\section{SINGULARIDADES DE LA PROTECCIÓN JURÍDICA CONTRA LA CONTAMINACIÓN ACÚSTICA}

Como hemos tenido ocasión de comentar, "el ruido constituye -en palabras de LÓPEZ RAMÓN con cita de SANZ SA- una particular forma de contaminación del aire, cuyos efectos sobre la salud humana son perniciosos, pese a que su percepción pueda parcialmente vincularse a elementos subjetivos". La protección contra esa contaminación, que podemos denominar con las notas de acústica, sonora o ruidosa, se hace así necesaria con plena cobertura normativa y con destacados efectos jurídicos. Por ello, en nuestro Ordenamiento jurídico son variadas las manifestaciones existentes con referencia a la protección contra la contaminación acústica.

Así, en el Derecho civil la defensa contra el ruido se canaliza por medio de las llamadas relaciones de vecindad, contemplándose el ejercicio de acciones tendentes a prohibir o, en su caso, limitar ruidos, con la consiguiente indemnización por los daños ocasionados como consecuencia de la producción de dichos ruidos. Es el caso de las previsiones contenidas en 
los artículos 446, 590 y 1908 del Código Civil, 7‥2 de la Ley de Propiedad Horizontal y 27 de la Ley de Arrendamientos Urbanos. Por lo demás, y como sostiene FERNÁNDEZ URZAINQUI, "el ruido puede ser objeto de consideración en la órbita del Derecho de vecindad como inmisión en la esfera jurídica ajena; en la del Derecho de daños, como factor desencadenante de daños corporales, económicos y morales; y en la del Derecho de contratos, como infracción de una conducta o cualidad contractualmente debidas".

En el Derecho penal se considera inequívocamente el adecuado silencio como bien jurídico protegido del tipo contemplado en el artículo 325 del vigente Código. Por consiguiente, la que se ha venido en denominar "higiene sonora" no es en modo alguno irrelevante desde el punto de vista de la protección jurídico-penal, pues, como mantiene VERCHER NOGUERA, la interdicción del ruido y la ulterior regulación del silencio constituye aspecto esencial en la concepción antropocéntrica del medio ambiente.

En el ámbito del Derecho administrativo, la calificación jurídica de determinadas actividades como molestas, en los casos en que se esté en presencia de una actuación incómoda por los ruidos o vibraciones que produzca, conlleva la puesta en marcha de un variado conjunto de técnicas policiales de intervención administrativa. Piénsese en cuestiones tales como la obligatoriedad de una especial licencia para el ejercicio de una concreta actividad, así como la adopción de cuantas medidas correctoras puedan resultar pertinentes y la determinación del correlativo sistema jurídico-sancionatorio. Y así, siguiendo a LÓPEZ RAMÓN, la lucha contra el ruido se articula por medio de un conjunto de medidas especiales tendentes a regular tanto las actividades productoras de ruido como el establecimiento de normas de contenido urbanístico. Entre las primeras pueden citarse actividades conflictivas procedentes de sectores diversos como el tráfico aéreo, el tráfico automóvil y las actividades de ocio; y por lo que respecta a las segundas es preciso distinguir los niveles sonoros de ruido y los Ilamados "usos acústicos del suelo". Pueden confrontarse, a este respecto, y entre otros preceptos y disposiciones, los artículos $2^{\circ}$ y $3^{\circ}$ del Reglamento de Actividades Molestas, así como las Leyes de Cataluña 13/1990, de Galicia 7/1997, del País Vasco 3/1998 y la nueva Ley de Cataluña 16/2002; los Decretos de Asturias 99/1985, de Baleares 20/1987, de Navarra 135/1989, de Castilla y León 3/1995, de Andalucía 74/1996, de Extremadura 19/1997, de Murcia 48/1998, de Madrid 78/1999 y de Andalucía 326/2003; y, en fin, numerosas Ordenanzas municipales reguladoras de la emisión y recepción de ruidos y de protección contra los mismos. Asimismo, y en palabras de ALEJANDRE DURÁN, "la nueva regulación de la Jurisdicción Contencioso-Administrativa y las novedades introducidas respecto a la 
legitimación, objeto, medidas cautelares y contenido del fallo amplían notablemente las facultades del juzgador para hacer efectiva la tutela frente al ruido". Son elocuentes, en este orden de ideas, los artículos 19, 25, 71 y 129 de la LJCA.

Finalmente, en el Derecho laboral las situaciones de ruido tienen un destacado componente en el ámbito de las condiciones de trabajo y en el desempeño de la relación jurídico-laboral, además de en el concreto asunto del control de la aplicación de las medidas preventivas y de protección de la seguridad y salud de los trabajadores. Como refleja GARCÍA PAREDES con cita de la Recomendación 156 de la Organización Internacional del Trabajo, "la preocupación de la incidencia del ruido en el lugar de trabajo es manifiesta, pero no sólo por su repercusión en ese espacio sino también por la que tiene en el medio ambiente general". Son significativos, en este sentido, los artículos 19 del Estatuto de los Trabajadores, 21 y 22 de la Ley General de Sanidad y 7ํy 12 de la Ley de Prevención de Riesgos Laborales, así como las Directivas 86/188/CEE y 89/391/CEE, y el Real Decreto 1316/1989, de 27 de octubre, sobre protección de los trabajadores frente a los riesgos derivados de la exposición al ruido durante el trabajo.

Por consiguiente, la lucha contra la contaminación sonora se articula a través de técnicas formales conducentes a limitar actividades productoras de ruido, entendidas éstas, según se ha visto, como una específica manifestación de las actividades molestas, aunque, como sugiere LÓPEZ RAMÓN, con unas particularidades propias: más subjetivas en las actividades molestas y más globales en la lucha contra el ruido; si bien de esta distinción no debe deducirse una equivalencia de lo tradicional con la obsolescencia ni de lo moderno con la eficacia, toda vez que la distinción apuntada se basa principalmente en el carácter ciertamente evolutivo de las normas relativas al fenómeno del ruido.

El Derecho, pues, concede suficiente protección frente a las inmisiones acústicas y, por su parte, los Tribunales de Justicia — como después se expondrá-, y según mantiene MARTÍ MARTÍ, "han conseguido Ilenar las lagunas legales sobre la base de una perfecta regulación y tratamiento del problema y de su acertada solución en cada caso concreto, castigando la inmisión y la falta de su control público». De aquí que el orden jurisdiccional contencioso-administrativo tenga, desde nuestro punto de vista, un papel preponderante en la fiscalización de situaciones productoras de contaminación sonora o ruidosa, particularmente en todos aquellos supuestos de inactividad de la Administración —en especial, de la Administración Local-, según se infiere de lo preceptuado en los artículos 29.1 in finø concordantes de la vigente LJCA. No se olvide, en este aspecto, y como apunta CASTELAO RODRÍGUEZ, que "la responsabilidad de reconducir a 
una actitud cívica de respeto a los derechos ajenos por los que causan estas molestias en la vía pública es responsabilidad de los servicios municipales".

\section{ESPECIAL CONSIDERACIÓN DE LA NUEVA LEY REGULADORA DEL RUIDO}

\subsection{Finalidad de la Ley 37/2003, de 17 de noviembre}

De una interpretación conjunta de los artículos $1^{\circ}$ y $5^{\circ}$ de la nueva Ley reguladora del Ruido (LR), se desprende que dicha nueva regulación legal tiene un doble objetivo: de una parte, prevenir, vigilar y reducir la contaminación acústica, a fin evitar y reducir los daños que de tal contaminación sonora puedan derivarse tanto para la salud humana, como para los bienes y para el medio ambiente; y, de otra, precisar la obligación de las Administraciones Públicas de informar a los ciudadanos acerca de la mencionada contaminación acústica, particularmente sobre los mapas de ruido y sobre los diferentes planes de acción contra ese tipo de contaminación.

De esta forma, la LR se basa en la Directiva 2002/49/CE del Parlamento Europeo y del Consejo, de 25 de junio de 2002, sobre evaluación y gestión del Ruido Ambiental, que, como se indica en la Exposición de Motivos de la propia LR, marca una nueva orientación respecto de las actuaciones normativas previas de la Unión Europea en materia de ruido. Y debe destacarse así que dicha Directiva tiene, en esencia, las siguientes finalidades: primeramente, concretar, mediante la elaboración de mapas de ruidos, la exposición al ruido ambiental; en segundo término, informar a la población sobre los niveles de ruido ambiental y sobre sus diferentes efectos; $y$, en tercer lugar, adoptar planes de acción por parte de los Estados miembros de la Unión Europea, a efectos de prevenir y, en su caso, reducir el mencionado ruido ambiental.

Sobre la base de las anteriores consideraciones, la LR, que excluye de su concreto ámbito de aplicación ciertos emisores acústicos -las actividades domésticas y el comportamientos de los vecinos (cuando la contaminación acústica que produzcan se encuentre dentro de los llamados "límites tolerables", de acuerdo con lo preceptuado en las ordenanzas municipales), así como las actividades militares y la actividad laboral-, contiene importantes definiciones con respecto al fenómeno acústico, lo que supone un acierto tanto desde el punto de vista jurídico constitucional como desde el plano de la técnica normativa. 
Se definen así extremos tales como el área acústica - «ámbito territorial delimitado por la Administración competente, que presenta el mismo objetivo de calidad acústica»-; la calidad acústica — «grado de adecuación de las características acústicas de un espacio a las actividades que se realizan en su ámbito»-; la contaminación acústica — «presencia en el ambiente de ruidos o vibraciones, cualquiera que sea el emisor acústico que los origine, que impliquen molestia, riesgo o daño para las personas, para el desarrollo de sus actividades o para los bienes de cualquier naturaleza, o que causen efectos significativos sobre el medio ambiente»-; el emisor acústico — «cualquier actividad, infraestructura, equipo, maquinaria o comportamiento que genere contaminación acústica»-; la evaluación acústica — «el resultado de aplicar cualquier método que permita calcular, predecir, estimar o medir la calidad acústica y los efectos de la contaminación acústica»—; el gran eje viario — «cualquier carretera con un tráfico superior a tres millones de vehículos por año»-; el índice acústico «magnitud física para describir la contaminación acústica, que tiene relación con los efectos producidos por ésta»—; el índice de emisión — «índice acústico relativo a la contaminación acústica existente en un lugar durante un tiempo determinado»-; el índice de inmisión — «índice acústico relativo a la contaminación acústica existente en un lugar en un tiempo determinado"—; el valor límite de inmisión — "valor del índice de inmisión que no debe ser sobrepasado en un lugar durante un determinado período de tiempo, medido con arreglo a unas condiciones establecidas"-; las zonas de servidumbre acústica — «sectores del territorio delimitados en las zonas de ruido, en los que las inmisiones podrán superar los objetivos de calidad acústica aplicables a las correspondientes áreas acústicas y donde se podrán establecer restricciones para determinados usos del suelo, actividades, instalaciones o edificaciones, con la finalidad de, al menos, cumplir los valores límites de inmisión establecidos para aquéllos"—; y, en fin, las zonas tranquilas en las aglomeraciones - «espacios en los que no se supere un valor, a fijar por el Gobierno, de un determinado índice acústicon-.

En materia de atribución de competencias, la LR diseña el siguiente esquema competencial: la Administración General del Estado tiene competencia para las infraestructuras viarias, ferroviarias, aeropotuarias y portuarias de ámbito estatal en relación con las diferentes actividades contempladas en el artículo 4ํㅜㄹ de dicha LR, con excepción de la delimitación del área o áreas acústicas integradas dentro del ámbito territorial de un mapa de ruido. En los restantes casos se estará a lo dispuesto en la legislación autonómica y, en su defecto, la competencia corresponderá a la la Comunidad Autónoma respectiva si el ámbito territorial del correspondiente mapa de ruido excede de un término municipal. Finalmente, corres- 
ponde a los Ayuntamientos la competencia en aquellos casos en que el ámbito territorial del mapa de ruido de que se trate no exceda de un término municipal $y$, además, la aprobación de las pertinentes ordenanzas sobre ruido, así como la adaptación de las ya existentes y del planeamineto urbanístico a las disposiciones de la LR.

\subsection{La regulaci n de la denominada calidad ac stica}

La LR, al ocuparse de la calidad acústica en los artículos $7^{\circ}$ a 16 , clasifica los tipos de áreas acústicas, contempla la fijación de objetivos en esa materia de calidad acústica, alude a la determinación de índices acústicos enumerando los diferentes emisores acústicos y determina los fines y el contenido de los mapas de ruido.

Señala la LR que las áreas acústicas deberán establecer, al menos, sectores del territorio con predominio de suelo de uso residencial, industrial, recreativo y de espectáculos, de uso terciario distinto del anterior tipo de uso, de uso sanitario, docente y cultural que requiera de especial protección contra la contaminación acústica, así como otros sectores del territorio afectados a sistemas generales de infraestructuras de transporte y especios naturales que, asimismo, precisen de especial protección contra la contaminación sonora.

Según previene el artículo $8^{\circ} .2$ de la LR, «para establecer los objetivos de calidad acústica se tendrán en cuenta los valores de los índices de inmisión y emisión, el grado de exposición de la población, la sensibilidad de la fauna y de sus hábitat, el patrimonio histórico expuesto y la viabilidad técnica y económica».

Es importante destacar que, conforme a lo preceptuado en el artículo 10.1 de la LR, "los sectores del territorio afectados al funcionamiento o desarrollo de las infraestructuras de transporte viario, ferroviario, aéreo, portuario o de otros equipamientos públicos que se determinen reglamentariamente, así como los sectores de territorio situados en el entorno de tales infraestructuras, existentes o proyectadas, podrán quedar gravados por servidumbres acústicas".

Seguidamente, la LR trata de los índices acústicos y, sobre este particular, el artículo 12.2 distingue los siguientes emisores acústicos: vehículos automóviles, ferrocarriles, aeronaves, infraestructuras viarias, infraestructuras ferroviarias, infraestructuras aeroportuarias, maquinaria y equipos, obras de construcción de edificios y de ingeniería civil, actividades industriales, actividades comerciales, actividades deportivo-recreativas y de ocio, y por último infraestructuras portuarias. 
Particular atención presta la LR a los denominados mapas de ruido, que, según previene el artículo 14.1, deberán aprobarse por la Administración competente con respecto a cada uno de los grandes ejes viarios y ferroviarios, de los grandes aeropuertos y de las aglomeraciones -que expresamente se determinan como municipios con población superior a cien mil habitantes-, así como las áreas acústicas en las que se incumplan los correspondientes objetivos de calidad acústica. Y es de significar, en este sentido, que el artículo 15.1 de la LR establece que dichos mapas de ruido tendrán como objetivos la evaluación global de la exposición a la contaminación acústica de una determinada zona, la realización de predicciones globales para esa zona y la adopción de planes de acción y de medidas correctoras que resulten precisas. A tales efectos, los propios mapas de ruido habrán de contener información acerca de cuestiones tales como el valor de los índices acústicos y de los objetivos de calidad acústica aplicables a las áreas acústicas afectadas, así como el grado de cumplimiento de esos objetivos de calidad sonora y el número estimado de personas, de viviendas, de colegios y de hospitales expuestos a la contaminación ruidosa en cada área acústica.

\subsection{La prevenci n de la contaminaci n sonora}

A nuestro juicio, uno de los más significativos aspectos de la LR se centra en las previsiones destinadas a regular la prevención y la contaminación acústica. Así, el artículo 18.1 preceptúa que las distintas Administraciones Públicas competentes intervendrán especialmente, en lo que a las previsiones de la propia LR se refiere, en actuaciones tales como el otorgamiento de la autorización ambiental integrada, la evaluación de impacto ambiental y la tramitación y concesión de licencias municipales de actividades clasificadas y de cuantas autorizaciones, licencias y permisos resulten necesarios para el ejercicio de actividades y para la instalación y funcionamiento de equipos y máquinas susceptibles de producir contaminación acústica. Para ello — puntualiza el artículo 18.2 de la LR-, dichas Administraciones asegurarán que se adopten cuantas medidas resulten pertinentes en orden a la prevención de la contaminación sonora y a que no se sobrepasen los valores límites aplicables, mediante el empleo de tecnologías de menor incidencia acústica.

A los anteriores efectos, la LR contempla en su artículo 19 que la correspondiente Administración podrá establecer un sistema de autocontrol de las emisiones acústicas, que se articulará a través de la obligación que tendrán los tituulares de los respectivos emisores acústicos de informar acerca de los resultados de la aplicación de ese sistema. 
En el mismo sentido de prevención de la contaminación acústica, el artículo 20.1 de la LR señala con carácter general que «no podrán concederse nuevas licencias de construcción de edificaciones destinadas a viviendas, usos hospitalarios, educativos o culturales si los índices de inmisión medidos o calculados incumplen los objetivos de calidad acústica que sean de aplicación a las correspondientes áreas acústicas». A la anterior previsión general se añaden como excepciones las zonas de protección acústica especial y las zonas de situación acústica especial, en las que sólo se exigirá el cumplimiento de los objetivos de calidad acústica en el espacio interior correspondiente.

Alude también la LR a los planes de acción en materia de contaminación acústica correspondiente a los ámbitos territoriales de los mapas de ruido. Estos planes, que deberán aprobarse previo trámite de información pública, tienen como objetivos, a tenor del artículo 23.1, afrontar globalmente las cuestiones relativas a la contaminación acústica en las distintas áreas acústicas, así como determinar acciones prioritarias a realizar en caso de superación de los valores límites de emisión o inmisión o de incumplimiento de los objetivos de calidad acústica y proteger a las zonas tranquilas contra el aumento de esa contaminación ruidosa.

\subsection{La correcci $n$ e inspecci $n$ de la contaminaci $n$ ac stica}

Dos son las cuestiones que merecen destacarse de la LR en materia de corrección e inspección de la contaminación acústica - materias éstas que, aunque en la LR aparecen reguladas en capítulos diferentes, entendemos no obstante que, por razones sistemáticas, deben ser objeto de tratamiento conjunto-: en primer lugar, la determinación de zonas de protección acústica especial y de zonas de situación acústica especial y, en segundo término, la concreción de los medios de inspección en materia de contaminación sonora.

En lo que respecta a la primera cuestión apuntada, el artículo 25.1 de la LR dispone que "las áreas acústicas en las que se incumplan los objetivos aplicables de calidad acústica, aun observándose por los emisores acústicos los valores límite aplicables, serán declaradas zonas de protección acústica especial por la Administración pública competente». Por su parte, el artículo 26 determina que "si las medidas correctoras incluidas en los planes zonales específicos que se desarrollen en una zona de protección acústica especial no pudieran evitar el incumplimiento de los objetivos de calidad acústica, la Administración pública competente declarará el área acústica en cuestión como zona de situación acústica especial». Es de significar que en estas últimas zonas se aplicarán medidas correctoras 
especícas, según previene el mismo artículo 26 in finque estarán destinadas a mejorar a largo plazo la propia calidad acústica.

En lo que atañe a la inspección en materia de contaminación acústica, el artículo 27.2 de la LR prevé la obligación de los titulares de los emisores acústicos de prestar a las autoridades competentes toda la colaboración precisa conducente a la realización de exámenes, controles, mediciones y labores de recogida de información, que en cada caso resulten pertinentes. En el supuesto de entradas domiciliarias, deberá estarse a lo dispuesto en el artículo $8^{\circ}$. 5 de la Ley Reguladora de la Jurisdicción Contencioso-Administrativa.

\subsection{Las infracciones y sanciones en materia de contaminaci n ruidosa}

En términos jurídico-constitucionales, una de las cuestiones que mayor interés ofrece la LR es la relativa al régimen sancionador. Especial relevancia tienen así extremos tales como la legalidad sancionadora, la culpabilidad, la presunción de inocencia y la tipicidad de í́citos sancionadores, así como la proporcionalidad de sanciones en materia de contaminación acústica. Téngase en cuenta, entre otros extremos, que en el ejercicio de la potestad sancionadora debe observarse el principio constitucional de presunción de inocencia, proclamado en el artículo 24.2 de la CE y contemplado, en lo que a este aspecto se refiere, en el artículo 137 de la Ley de Régimen Jurídico de las Administraciones Públicas y del Procedimiento Administrativo Común, pues según reiterada jurisprudencia del TC —entre otras, sentencias de la Sala Primera de 20 de diciembre de 1990 y de la Sala Segunda de 21 de julio de 1997-, la traslación de dicha presunción de inocencia a la esfera del Derecho Administrativo sancionador cobra sentido cuando la Administración fundamenta su resolución en una presunción de culpabilidad del sancionado carente de elemento probatorio alguno, no siendo procedente en modo alguno la imputación de responsabilidades sancionadoras con base en datos probatorios no constatados suficientemente.

La LR, siguiendo la clásica clasificación tripartita del Derecho administrativo sancionador, distingue los siguientes tipos de infracciones: muy graves, graves y leves. Entre las primeras se tipifican la producción de contaminación acústica por encima de los valores límite establecidos en zonas de protección acústica especial y en zonas de situación acústica especial; la superación de los valores límite que sean aplicables; el incumplimiento de las condiciones establecidas en la autorización ambiental integrada, en las licencias de actividades clasificadas y en las diferentes figuras de intervención administrativa; $y$, en fin, el incumplimiento de los requisitos relati- 
vos a la protección de las edificaciones contra el ruido, cuando se haya puesto en peligro grave la seguridad o la salud de las personas. Es de significar que para este tipo de infracciones, la LR contempla como posibles sanciones las de multa de 12.001 euros hasta 300.000 euros, así como la revocación de la autorización ambiental integrada o de la correspondiente figura de intervención administrativa, la clausura definitiva - total o parcial- de las instalaciones, la clausura temporal - total o parcial- de las instalaciones por un período no inferior a dos años ni superior a cinco, el precintado temporal o definitivo de equipos y máquinas, la prohibición temporal o definitiva del desarrollo de actividades y, por último, la publicación del nombre de los infractores; sanción ésta última rescatada de ciertos regímenes sancionadores preconstitucionales y que ciertamente requiere para su concreta imposición considerable cautela y detenida reflexión, en términos de protección del derecho a la intimidad, consagrado en el artículo 18.1 de la CE.

Como infracciones graves, la LR se refiere a la superación de los valores límite que resulten aplicables, cuando no se haya en puesto en peligro grave la seguridad o la salud de las personas; el incumplimiento de las condiciones establecidas en la autorización ambiental integrada, en las licencias de actividades clasificadas y en las diferentes figuras de intervención administrativa, cuando tampoco se hayan en puesto en peligro grave las referidas seguridad o salud de las personas; la ocultación o alteración maliciosas de datos relativos a la contaminación acústica aportados a los expedientes administrativos destinados a la obtención de autorizaciones y licencias administrativas; el impedimiento, el retraso o la obstrucción a la actividad inspectora o de control de las Administraciones Públicas; $y$, finalmente, la no adopción de medidas correctoras requeridas por la correspondiente Administración. Para estas infracciones graves, la LR determina como posibles sanciones las de multa de 601 euros hasta 12.000 euros, la suspensión de la vigencia de la autorización ambiental integrada o de la correspondiente figura de intervención administrativa y la clausura temporal - total o parcial- de las instalaciones por un período máximo de dos años.

Entre las infracciones leves, la LR alude a la no comunicación a la Administración competente de los datos requeridos por ésta, dentro de los plazos establecidos al efecto; la instalación o comercialización de emisores acústicos sin acompañar la información sobre sus índices de emisión; y, en último lugar - y como infracción genérica y residual, de dudosa constitucionalidad, a nuestro modo de ver, por no ajustarse expresamente a una ineludible definición de conductas consustancial al principio de tipicidad (Iex cer) ka, el incumplimiento de las previsiones contenidas en la propia LR, «cuando no esté tipificado — se dice en el artículo 28.4,c)— como infrac- 
ción muy grave o grave. La LR establece únicamente como posible sanción para las mencionadas faltas leves la de multa de hasta 600 euros.

En lo que respecta al principio de proporcionalidad de las sanciones -fundamental conforme a lo previsto en el artículo 25 de la CE-, la nueva LR señala como criterios a tener en cuenta las circunstancias del responsable, la entidad del daño causado, el grado de molestia ocasionada, la intencionalidad o negligencia y la reincidencia o participación. Para la concreción de este último criterio, debe estarse a lo dispuesto en el artículo $131.3, c)$ de la Ley de Procedimiento Administrativo Común. Por consiguiente, las distintas Administraciones Públicas en cada caso competentes — según las previsiones contenidas en el artículo 30 de la LR- habrán de observar los apuntados criterios a la hora de realizar un adecuado juicio de proporcionalidad para imponer la pertinente sanción administrativa.

Dichas Administraciones competentes, según dispone el artículo 31 de la LR, pueden adoptar una medida provisional para asegurar la eficacia de la resolución final sancionadora. Tienen así plena cobertura normativa medidas cautelares tales como el precintado de aparatos, equipos o vehículos; la clausura temporal - total o parcial- de las instalaciones o del establecimiento en cuestión; la suspensión temporal de la autorización ambiental integrada, de las licencias de actividades clasificadas y de las diferentes figuras de intervención administrativa; y las medidas de corrección o control que impidan la continuidad en la producción del riesgo o del daño de que se trate.

\section{DECISIONES JURISDICCIONALES}

Y TRATAMIENTO JURISPRUDENCIAL

\subsection{Antecedentes y situaci n actual}

Tanto la dispersidad normativa existente en materia de protección contra las inmisiones sonoras, como la gran repercusión social que ha producido esta misma cuestión, especialmente en los últimos años, unido todo ello a la inactividad de algunas Administraciones municipales con respecto a las diversas demandas promovidas por particulares con la pretensión de que cesaran distintas actividades sonoras — sobre todo en el ámbito de la contraposición del derecho al descanso con el derecho al ocio y a la diversión nocturna basada en hechos y acontecimientos productores de ruido, en sus muy variadas manifestaciones externas-, son circunstancias que han influido decisivamente, con mayor o menor intensidad - según las épocas y según también las distintas zonas geográficas-, en la evolución jurisprudencial habida sobre el particular. 


\subsubsection{Jurisdicci n del Tribunal Europeo de Derechos Humanos}

El TEDH, en sentencias de 21 de febrero de 1990 (caso Powell y Rayner contra el Reino Unido), 9 de diciembre de 1994 (caso López Ostra contra el Reino de España), 19 de febrero de 1998 (caso Guerra contra Italia) y 2 de octubre de 2001 (caso del aeropuerto de Heathrow), ha declarado lo que a continuación se dice:

"Lo determinante es si las autoridades nacionales han adoptado las medidas necesarias para garantizar la protección efectiva de la vida privada y familiar de los interesados ... Los atentados graves al medio ambiente pueden afectar al bienestar de las personas y privarlas del disfrute de su domicilio perjudicando su vida privada y familiar».

Asimismo, debe destacarse como más reciente la sentencia de TEDH de 16 de noviembre de 2004 en la que, entre otros extremos, se indica que "el individuo tiene derecho a que se respete su casa, lo que significa el respeto no sólo del área física, sino también la tranquila y pacífica posesión de esa área».

\subsubsection{Jurisdicci n constitucional}

EI TC se ha ocupado de la temática de que venimos tratando, entre otras, en la sentencia de la Sala Segunda 22/1984, de 17 de febrero, y en las del Pleno 290/2000, de 30 de noviembre, y 119/2001, de 24 de mayo. En ésta última se pone de relieve lo que seguidamente se transcribe:

«En determinados casos de especial gravedad, ciertos daños ambientales aun cuando no pongan en peligro la salud de las personas, pueden atentar contra su derecho al respeto de su vida privada y familiar, privándola del disfrute de su domicilio, en los términos del art. 8.1 del Convenio de Roma ... Una exposición prolongada a unos determinados niveles de ruido, que puedan objetivamente calificarse como evitables e insoportables, ha de merecer la protección dispensada al derecho fundamental a la intimidad personal y familiar, en el ámbito domiciliario, en la medida en que impidan o dificulten gravemente el libre desarrollo de la personalidad, siempre y cuando la lesión o menoscabo provenga de actos u omisiones de entes públicos a los que sea imputable la lesión producida».

Mención especial merecen las sentencias del TC 16/2004, de 23 de febrero, y $25 / 2004$, de 26 de febrero, que posteriormente serán objeto de particular atención. 


\subsubsection{Jurisdicci n civil}

En la jurisdicción civil pueden mencionarse, entre otras, las siguientes sentencias: de la Sala Primera del Tribunal Supremo de 5 de mayo de 1949, 24 de enero de 1954, 30 de octubre de 1955, 6 de abril de 1957, 22 de diciembre de 1972, 17 de febrero de 1968, 12 de diciembre de 1980, 14 de noviembre de 1984, 16 de febrero de 1987, 3 de septiembre de 1992, 28 de septiembre de 1993, 18 de mayo de 1994, 13 de mayo de 1995 y 2 de febrero de 2001; de la Sala Primera de la Audiencia Territorial de Barcelona de 25 de marzo de 1988, y de la Audiencias Provinciales de Valencia de 2 de noviembre de 1990, de Toledo de 28 de diciembre de 1994, de Palma de Mallorca de 29 de enero de 1996, de Murcia de 24 de mayo de 1997, de Salamanca de 16 de octubre de 1997, de Córdoba de 26 de enero de 1998, de la Sección 1a de Barcelona de 3 de marzo de 1999, de la Sección 5a de Vizcaya de 24 de junio de 1999, de la Sección 1a de Pontevedra de 5 de abril de 1999, de Segovia de 22 de diciembre de 1999, de Lérida de 15 de septiembre de 2000, de la Sección 14a de Madrid de 20 de noviembre de 2000, de La Rioja de 10 de enero de 2001, de la Sección $5^{\text {a }}$ de Alicante de 31 de mayo de 2001, de la Sección $2^{\text {a }}$ de Burgos de 29 de noviembre de 2001, de la Sección $2^{\text {a }}$ de Cáceres de 16 de enero de 2002, de la Sección 12a de Barcelona de 27 de marzo de 2002, de la Sección $1^{1 \underline{a}}$ de Castellón de 3 de mayo de 2002, de la Sección $1^{1}$ a de Zamora de 11 de julio de 2002 y de la sección $2^{a}$ de la Audiencia Provincial de Córdoba de 27 de abril de 2004; y, finalmente, de los Juzgados de Primera Instancia núm. 46 de Barcelona de 5 de noviembre de 2001, núm. 13 de Sevilla de 11 de diciembre de 2001, núm. 2 de Murcia de 8 de febrero de 2002 y núm. 6 de Córdoba de 25 de febrero de 2003. Debe significarse que la expresada sentencia de la Sala Primera del Tribunal Supremo de 12 de diciembre de 1980 es del siguiente tenor literal:

«Si bien el Código Civil no contiene una norma general prohibitiva de toda inmisión perjudicial o nociva, la doctrina de esta Sala y la científica entienden que puede ser inducida de una adecuada interpretación de la responsabilidad extracontractual impuesta por el art. 1902 de dicho Cuerpo legal y en las exigencias de una correcta vecindad y comportamiento según los dictados de la buena fe que se obtienen por generalización analógica de los arts. 590 y 1908 del Código Civil, pues regla fundamental es que "la propiedad no puede llegar más allá de lo que el respeto al vecino determina»... A la luz de estas pautas orientadoras es manifiesto que el ejercicio de una industria, no obstante su interés para la economía nacional, debe desenvolverse en su funcionamiento guardando el debido respeto a la propiedad ajena, ya que, según autorizada opinión, el ordenamiento jurídico no puede permitir que una forma concreta de actividad económica, por el solo hecho de represen- 
tar un interés social, disfrute de un régimen tan singular que se le autorice para suprimir o menoscabar, sin el justo contravalor, los derechos de los particulares, antes por el contrario el interés público de una industria no contradice la obligación de proceder a todas las instalaciones precisas para evitar los daños, acudiendo a los medios que la técnica imponga para eliminar las inmisiones".

\subsubsection{Jurisdicci n penal}

Por lo que respecta a la jurisdicción penal son de destacar, entre otras, las sentencias de la Sala Segunda del Tribunal Supremo de 24 de febrero de 2003, que confirmó íntegramente la de la Audiencia Provincial de Palencia de 9 de noviembre de 2000, y las de las Audiencias Provinciales de Zaragoza —Sección 3 $3^{\text {a }}$ - de 13 de mayo de 2002 y de Granada de 15 de enero de 2003, así como la del Juzgado de lo Penal núm. 5 de Granada de 24 de junio de 2002.

En la precitada sentencia de la Audiencia Provincial de Palencia, tras determinarse los distintos elementos caracterizadores del delito contra el medio ambiente, tipificado en el artículo 325.1 del Código Penal —el elemento descrptivo (en este caso, la realización directa de ruidos en la atmósfera), el elemento normativo (la vulneración de leyes u otras disposiciones de carácter general protectoras del medio ambiente) y el elemento valorativo (que es fundamental para distinguir el ilícto penal del ilícito administrativo y que es el que determina el resultado del peligro producido)—, se adopta un pronunciamiento condenatorio sobre la base de una declaración de hechos probados en la que, entre otros extremos, se pone de manifiesto lo siguiente:

"La exposición de una persona a los niveles de ruido entre 30 y 40 DBA, reiterada, pero no permanente, de forma que se corresponde con las noches de los fines de semana, durante un período de tiempo que no tiene necesariamente que ser superior a 9 meses, y así también la exposición a tal nivel de ruido durante 4 noches seguidas, puede causar afectaciones, dependiendo de la sensibilidad que cada persona pueda tener, de tipo psíquico y psicológico, con desarrollo de trastorno de sueño en forma de insomnio, que se originan cuando los niveles sonoros impiden conciliar el sueño o provocan despertares tempranos, alteraciones que alteran el ritmo de vida normal pudiendo provocar estados de fatiga, cansancio, irritabilidad, disminución de atención y concentración y consecuentemente de los rendimientos laborales o escolares, pudiéndose llegar al desarrollo de brotes psicóticos (con cuadros alucinatorios, delirantes y de alteraciones de conciencia), o a la existencia de síntomas vege- 
tativos, tales como taquicardias, hipertermia, aumento de la sensación de hambre, hiperfagia, cefaleas, gastralgias, ... Las consecuencias de la afectación aludida en niños puede producir trastornos de conducta; en mujeres embarazadas puede interferir en el embarazo y originar un parto prematuro además de someter a estrés al feto que le supone una situación de especial riesgo durante el período neonatal, y así también tal afectación puede producir el agravamiento de enfermedades preexistentes como la esclerosis".

\subsubsection{Jurisdicci n contencioso-administrativa}

En la jurisdicción contencioso-administrativa cabe hacer referencia, entre otras, a las siguientes sentencias: de la antigua Sala Cuarta del Tribunal Supremo de 13 de diciembre de 1982, 27 de diciembre de 1984 y 13 de diciembre de 1985, de la Sección $4^{\text {a }}$ de la Sala Tercera del Tribunal Supremo de 27 de junio de 1992, 22 de septiembre de 1993, 20 de septimbre de 1994, 10 de noviembre de 1995, 10 de junio de 1996, 16 de diciembre de 1999, 20 de septiembre de 2000 y 4 de febrero de 2002, de la Sección $5^{\text {a }}$ de la misma Sala de 7 de noviembre de 1997 y 13 y 19 de octubre de 1998, así como de la Sección 6a de 7 de mayo de 2002 y de la Sección $7^{a}$ de 18 de noviembre de 2002; de las Salas de lo Contencioso-Administrativo de los Tribunales Superiores de Justicia de Cataluña - Sección $3^{\text {a }}$ - de 20 de diciembre de 1993 y Sección $2^{\text {a }}$ de 6 de septiembre de 2002, de La Rioja de 13 de enero de 1997, de Madrid-Sección $2^{2}$ - de 18 de junio de 1998, de Asturias-Sección $1^{\text {a }}$ — de 20 de noviembre de 1998, de Valencia-Sección $3^{\mathrm{a}}$ - de 1 de junio de 1999 y Sección 1a de 9 de julio de 2000, de BalearesSección $1^{1}$ - - de 29 de julio de 1999, de Castilla-La Mancha- Sección $1^{\text {a }}$ de 13 de julio de 1999, 7 de abril de 2000 y 10 de febrero de 2003, de Murcia-Sección $2^{\mathrm{a}}$ - de 29 de octubre de 2001 y de Andalucía- Sección $3^{\text {a }}$ de Sevilla —de 29 de marzo de 2001- Sección 1 ${ }^{\text {a }}$ de Sevilla —de 29 de octubre de 2001 y de Málaga de 16 de junio de 2003, así como de Asturias-Sección 2a — de 17 de noviembre de 2003 y de Castilla y LeónSala de Burgos — de 14 de mayo de 2004; y, en fin, de los Juzgados de lo Contencioso-Administrativo núm. 1 de Segovia de 20 de marzo de 2002, núm. 2 de Valencia de 30 de octubre de 2002, núm. 1 de Granada de 27 de enero de 2003 y núm. 5 de Sevilla de 31 de marzo de 2003.

Debe resaltarse que en algunas de las indicadas sentencias se reconoce que los ruidos pueden llegar a causar molestias insoportables, desequilibrios físicos, morales y psíquicos e, incluso, la depreciación de los inmuebles, lo que tiene una destacada relevancia jurídica a los efectos de la determinación tanto de una supuesta inactividad de las 
Administraciones implicadas como, en su caso, de la correspondiente declaración de indemnización por responsabilidad patrimonial de dichas Administraciones, en los términos establecidos, respectivamente, en los artículos 29 de la Ley Reguladora de la Jurisdicción ContenciosoAdministrativa y 139 a 141 de la Ley de Régimen Jurídico de las Administraciones Públicas y del Procedimiento Administrativo Común. De este modo, en la aludida sentencia de la Sala Jurisdiccional de Sevilla de 29 de octubre de 2001 se indica lo que sigue:

"Siendo pausible todas las medidas legislativas, las encaminadas a paliar los efectos nocivos, las preventivas educativas y alternativas que ponen de manifiesto la voluntad municipal de hacer frente al problema, la prueba practicada en estos autos - testifical y emisión de informes de la actuación de la policía municipal- ponen de manifiesto que la permisividad por una parte y la inactividad municipal por otra contribuyen a las molestias y ruidos que impiden el descanso de los vecinos de la zona. En efecto no basta con regular mediante las oportunas ordenanzas la protección del medio ambiente, la prohibición de venta de alcohol fuera de los establecimientos que tengan licencia para ello, la limpieza en los lugares públicos, sino que con los medios adecuados hacer efectivas dichas Ordenanzas impidiendo se sobrepasen los límites de emisión de ruidos procediendo al cierre de los establecimientos que lo incumplan e incluso dispersando las concentraciones de jóvenes cuando se sobrepasan dichos límites. No se trata de ejercer una represión policial, sino dentro de los límites de dicha función denunciar una y otra vez las infracciones administrativas, incomodar y disuadir sin descanso a los jóvenes en sus comportamientos y no favorecer mediantes cortes de tráfico y vallas dichas concentraciones porque los derechos de los jóvenes a expresarse y reunirse encuentran sus límites en los derechos de los demás ciudadanos a la libre circulación, al descanso y a la propia vida entendida en un sentido amplio no solo físico, que se ven menoscabados al no adoptar la Administración demandada las medidas adecuadas y suficientes para paliar al menos en parte los efectos negativos concretados en el presente proceso".

\subsubsection{Jurisdicci n social}

Por último, en lo que atañe a la jurisdicción social pueden citarse, entre otras, las siguientes sentencias: de la Sala Cuarta del Tribunal Supremo de 6 de octubre de 1995 y 16 de enero de 1996; y de las Salas de lo Social de los Tribunales Superiores de Justicia de Cataluña de 29 de diciembre de 1995, del País Vasco de 9 de julio de 1996, de Galicia de 30 de mayo de 2000, de Valencia de 27 de septiembre de 2001, de Cantabria de 18 de octubre de 2001 y, finalmente, de Castilla y León de 29 de octubre de 
2002. Debe hacerse notar, a modo de ejemplo, que en la referida sentencia del Tribunal Supremo de 19 de enero de 1996 se declara lo siguiente:

«En materia de protección laboral contra el ruido son tres los niveles existentes: el 1ㅇ) consiste en proporcionar adecuada información y proveer de protectores auditivos a los trabajadores que lo solicitan a partir de 80 decibelios; el 2o) comporta la obligación de proporcionar dichos protectores auditivos a todos los trabajadores expuestos a ruidos que alcancen la intensidad de 85 decibelios y a proporcionar, a los mismos, controles médicos periódicos cada tres años; y el 3의 consiste en la adopción de medidas técnicas para la disminución del ruido y, al propio tiempo, medidas preventivas, entre las que se encuentran el uso obligatorio de protectores auditivos para los trabajadores y el necesario control médico anual».

5.2. Problem tica de la adopci n de medidas cautelares contenciosoadministrativas en materia de contaminaci $n$ ac stica

Hemos sostenido en cierta ocasión que en el ya citado Derecho público de las inmisiones y, particularmente, en la protección frente a inmisiones ilegales auspiciadas por la inactividad de la correspondiente Administración, la Jurisdicción Contencioso-Administrativa tiene una función de especial preponderancia. $Y$ en este ámbito procesal existe una cuestión de destacada trascendencia práctica, no exenta de una secular polémica que, gracias a la más reciente evolución jurisprudencial, ha venido superándose: nos estamos refiriendo a la posibilidad de adoptar medidas cautelares positivas como consecuencia de la formulación de demandas promovidas contra la inactividad de la Administración, pretendiendo la cesación de inmisiones acústicas y ruidosas.

Téngase en cuenta que la cuestión apuntada no es nueva ni exclusiva de nuestro sistema contencioso-administrativo. Así, como recuerda GONZÁLEZ-VARAS, «la jurisprudencia española ha reconocido que la jurisdicción contencioso-administrativa puede disponer órdenes de condena cautelares frente a la Administración»; cuestión ésta de la que, por lo demás, ya existían antiguos precedentes en el Derecho comparado. Es el caso de un auto del Tribunal Superior Contencioso-Administrativo de Münster, de fecha 14 de marzo de 1957, que contenía la siguiente doctrina:

"La medida cautelar positiva no puede excluirse en el proceso administrativo; más bien, al contrario, lo que existe es un interés urgente en su introducción procesal, porque si no las garantías procesales sólo se otorgan de forma deficiente». 


\subsubsection{Resoluciones del Tribunal Supremo}

Como punto de partida debemos centrarnos en la entonces novedosa doctrina contenida en la sentencia de la Sala Tercera, Sección $1^{\underline{a}}$, del Tribunal Supremo de 25 de abril de 1989, resultando también de cita obligada las sentencias de la misma Sala de 27 de marzo de 1990, 12 de diciembre de 1995 y 24 de julio de 1998, a cuyo tenor:

"La apertura clandestina de establecimientos comerciales o industriales sin la necesaria licencia de actividades obligan a adoptar de plano y con efectividad inmediata la medida cautelar de clausurar el establecimiento o paralizar la actividad, con el fin de evitar que se prolongue en el tiempo la posible transgresión de los límites impuestos por exigencias de la convivencia social, hasta la obtención de la oportuna licencia que garantice la inexistencia de infracciones".

En esta misma línea de argumentación jurídica que estamos comentando, favorecedora a la adopción de medidas cautelares positivas en materia de inactividad de la Administración con respecto a la emisión de ondas sonoras productoras de molestias, deben constatarse las sentencias de la Sala Tercera del Tribunal Supremo de 30 de octubre y 22 de noviembre de 2000.

\subsubsection{Resoluciones de otros rganos jurisdiccionales}

Resulta particularmente significativo, entre otros de distintos Juzgados, el auto del Juzgado de lo Contencioso-Administrativo núm. 2 de Albacete de 28 de diciembre de 2001, en uno de cuyos fundamentos jurídicos, a propósito de la solicitud de la medida cautelar consistente en que se obligara a una Administración municipal a adoptar las medidas tendentes a que cesaran los ruidos insoportables procedentes de una discoteca que impedían descansar por la noche a un matrimonio de ancianos, se determina lo siguiente:

«Resta por abordar la alegada, por la defensa del Ayuntamiento, improcedencia de que se adopte por este Órgano jurisdiccional la pretendida medida cautelar, al tener dicho acto - se dice- un contenido de carácter negativo. No es posible, sin embargo, compartir ese planteamiento, por cuanto que de una interpretación conjunta e integradora de los artículos 24.1 de la Constitución y 129 y 130 de la Ley Jurisdiccional se desprende la posibilidad de adoptar la suspensión cautelar de actuaciones como la aquí cuestionada, en razón de las siguientes consideraciones: en primer lugar, porque la denominada justicia cautelar forma parte inequívoca del derecho a una tutela judicial efectiva sin indefensión, careciendo de base constitucional y legal 
introducir una limitación en esa tutela cautelar por la sola circunstancia de que se esté impugnando una aparente actuación negativa; en segundo término, porque con arreglo a una interpretación gramatical del mencionado artículo 129.1, la adopción de medidas cautelares se basa en una regulación amplia de la tutela cautelar, sin limitaciones ni restricciones de ningún género; y, por último, porque la acción o la inactividad de la Administración en el ámbito del que se ha venido en denominar "Derecho de las inmisiones" y la materia de ruidos constituye un destacado aspecto de este sector del Ordenamiento jurídico-, se traduce en una pretensión prestacional a favor de los directa y supuestamente afectados, y ante una respuesta administrativa frente a esa pretensión — sea tanto estimatoria como denegatoria-, es jurídicamente admisible, en términos favorables a una efectiva tutela cautelar sin indefensión, la suspensión cautelar de la actividad que ha motivado el presente recurso, como se infiere de la doctrina jurisprudencial de la Sala Tercera del Tribunal Supremo, fundamentalmente desde la sentencia de la Sección 1a de dicha Sala de fecha 25 de abril de 1989, así como de la más reciente jurisprudencia del Tribunal Constitucional contenida en las sentencias de 13 de febrero de 1998 y 22 de julio de 1999, y del Tribunal Europeo de Derechos Humanos, en su sentencia de 9 de diciembre de 1994, de la que puede deducirse que la relevancia de la inactividad de la Administración ante las denuncias de los ciudadanos en materia de contaminación acústica, no impide la suspensión cautelar de la correspondiente actuación —que, en su caso, haya dado lugar a la inactividad de la Administración cuestionada, al poderse ver afectado el derecho a la intimidad personal y familiar de los ciudadanos, en la vertiente del que se ha venido en llamar «derecho a la intimidad domiciliaria». Por lo que procede estimar la pretendida adopción de medidas cautelares en el recurso contencioso-administrativo de la referencia, debiéndose, en consecuencia, adoptar por el Ayuntamiento demandado las medidas precisas tendentes a que no se produzcan las molestias denunciadas por la parte recurrente, sin perjuicio de lo que, en su día, se resuelva por este Órgano jurisdiccional en el citado recurso".

\section{REFERENCIA A LA MÁS RECIENTE DOCTRINA JURISPRUDENCIAL}

\subsection{Las Itimas sentencias del Tribunal Constitucional: sentencias 16/2004, de de 23 de febrero, y 25/2004, de 26 de febrero.}

Según se ha visto con anterioridad, la jurisprudencia constitucional determina la concurrencia de tres notas características para que el fenómeno del ruido tenga relevancia constitucional, en la medida en que puedan verse afectados algunos de los derechos reconocidos en el artículo 18 
de la CE. Dichas notas características son las siguientes: en primer lugar, la exposición prolongadaa un nivel de ruido evitable e insoportable; en segundo término, la imposibilidad o dificultad del libre desarrollo de la personalidad; y, por último, la existencia de una lesión o perjuicio que proviene de una acción u omisión atribuible a un ente integrado en el sector público.

Partiendo de las anteriores premisas, en la apuntada sentencia 16/2004 el TC aborda el problema del principio constitucional de legalidad dentro del ámbito sancionador y con respecto a la temática de la contaminación acústica. El caso en cuestión aludía a la sanción impuesta por un Ayuntamiento a los propietarios de una discoteca sobre la base de lo dispuesto en una Ordenanza municipal del año 1992, sobre protección contra la contaminación acústica; forma de proceder ésta que fue confirmada en la correspondiente vía judicial contencioso-administrativa. $Y$ no considerando conforme a la CE dicha confirmación, la representación de la mencionada discoteca recurrió en amparo constitucional, al considerar que se había vulnerado el referido principio de legalidad sancionadora. La solución mayoritaria del TC, pues se formuló por tres Magistrados un voto particular conjunto favorable a la estimación del recurso de amparo interpuesto, apreció que es constitucional aplicar al caso debatido no tanto el Reglamento de Actividades Molestas de 1961 como especialmente la Ley de Protección del Ambiente Atmosférico de 1972, por lo que, desde el punto de vista formal, quedaban aseguradas las exigencias constitucionales derivadas de ese principio de legalidad en relación con el Derecho administrativo sancionador. Se consagra así la siguiente doctrina jurisprudencial:

«El art. 25.1 de la CE obliga al legisladora regular por sí mismo los tipos de infracción administrativa y las sanciones correspondientes, en la medida necesaria para dar cumplimiento a la reserva de Ley. Desde otro punto de vista, y en tanto aquella regulación no se produzca, no es lícito, a partir de la $\mathrm{CE}$, tipificar nuevas infracciones ni introducir nuevas sanciones o alterar el cuadro de las existentes por una norma reglamentaria cuyo contenido no esté suficientemente predeterminado o determinado por otra de rango legal... Pero este Tribunal ha considerado acorde con la CE el supuesto en que la norma reglamentaria posconstitucional se limita, sin innovar el sistema de infracciones y sanciones en vigor, a aplicar ese sistema preestablecido al objeto particularizado de su propia regulación material. No cabe entonces hablar propiamente de remisión normativa a favor de aquella disposición, puesto que la remisión implica la potestad conferida por la norma de reenvío de innovar, en alguna medida, el ordenamiento por parte de quien la utiliza. En realidad, se trata más bien de una reiteración de las reglas sancionadoras establecidas en otras normas más generales, por aplicación a una materia singularizada incluida en el ámbito genérico de aquéllas». 
Por su parte, la sentencia del TC $25 / 2004$ se refiere a un supuesto en el que determinada Corporación Municipal impuso una sanción a una discoteca, por contaminación acústica, empleando como cobertura formal para ello no una Ordenanza ad hoc-como en el caso anterior-, sino una Ordenanza genérica de protección del medio ambiente, sosteniéndose en la actuación administrativa objeto de la controversia suscitada que el anclaje legal de tal Ordenanza se encontraba en la Ley Orgániza de Seguridad Ciudadana de 1992. A este respecto, el TC, que aquí sí estimó el recurso de amparo promovido, declara lo que sigue:

"Ciertamente, la eliminación o disminución de los ruidos y las vibraciones de las fuentes productoras en las distintas instalaciones y actividades sujetas a la misma, para situarlas dentro de límites que los hagan tolerables, se encuentra encaminada a procurar una mayor tranquilidad a los vecinos, $y$, en este sentido, puede considerarse relacionada con la seguridad pública, objeto preciso de la regulación contenida en la Ley Orgánica 1/1992. Sin embargo, la Ordenanza no deja de establecer un conjunto de reglas que protege la tranquilidad ciudadana a través de una intervención administrativa que no resulta extraordinaria y que se desarrola de manera constante y regular, permitiendo el funcionamiento normal de las actividades afectadas de modo que los ruidos y vibraciones que produzcan no alteren la calidad de vida de los ciudadanos; finalidad en la que se inserta incluso el régimen sancionador, en el que no se pueden atisbar reacciones para situaciones que puedan ser consideradas de riesgo extraordinario. Por tanto, el fundamento de la Ordenanza no se puede incardinar propiamente dentro del concepto de "seguridad pública» ni, en suma, en el ámbito estricto de cobertura de la Ley Orgánica de protección de la seguridad ciudadana».

6.2. Las Itimas sentencias del Tribunal Supremo: sentencias de la Sal Primera de 29 de abril de 2003 y de la sala Tercera de 10 de abr 29 de mayo y 23 de junio de 2003 y 27 de abril de 2004.

El Tribunal Supremo ha tenido ocasión recientemente de pronunciarse acerca de las inmisiones acústicas en cinco ocasiones: nos estamos refiriendo a la sentencia de la Sala Primera de 29 de abril de 2003, así como a las de la Sala Tercera de 10 de abril, 29 de mayo y 23 de junio de 2003 y 27 de abril de 2004.

En la sentencia de la Sala de lo Civil del Tribunal Supremo de fecha 29 de abril de 2003 se afirma lo que sigue:

«La competencia del orden jurisdiccional contencioso-administrativo sólo es aplicable cuando sea demandada de forma exclusiva la Administración, conforme a la Ley reguladora de la jurisdicción contencioso-administrativa, así 
como a la Ley 30/1992 de 26 de noviembre, sobre Régimen Jurídico de las Adminitraciones Públicas y del Procedimiento Administrativo Común en cuanto al régimen de responsabilidad patrimonial, pero no en los supuestos en que, junto a la Administración se demanda y existe una relación de corresponsabilidad en los hechos (vis atractidea este sector jurisdiccional)... El planteamiento que se hace en el caso sobre la tipología de las intromisiones ilegítimas pretendiendo implícitamente que se circunscriba a los concretos supuestos del art. 7 de la Ley Orgánica 1/1982 de 5 de mayo (protección del derecho al honor, a la intimidad y a la propia imagen) —excluyendo del ámbito del derecho a la intimidad las inmisiones sonoras excesivas padecidas en el propio domicilio - ya fue rechazado por esta Sala (sentencias de 28 de octubre y 4 de noviembre de 1996, entre otras) que ante la fuerza expansiva de los derechos fundamentales $y$, con apoyo en el propio texto normativo, se atiene a la realidad de su vulneración más que a los medios con que aquélla se realice. Ello es particularmente exigible en aquellos derechos fundamentales, como el de la intimidad, cuya noción o determinación conceptual fuera de su vaga definición como "derecho a ser dejado en paz», equivalente a derecho a la soledad y a la tranquilidad, obliga a caracterizarlos desde la perspectiva de los actos concretos que inciden en su contenido o núcleo esencial. En este sentido, la protección a la intimidad no queda reducida a la evitación y proscripción de la divulgación de la vida privada o la penetración no autorizada en el ámbito en que se desarrolla la vida privada. Nuevas formas o nuevos procedimientos que alteren gravemente la paz familiar y el entorno en que se desarrolla la vida íntima o privada constituyen manifestaciones de intromisión ilegítima frente a las cuales cabe y es obligada la tutela judicial».

En las dos aludidas sentencias de la Sección $7^{a}$ de la Sala de lo Contencioso-Administrativo del Alto Tribunal, de fechas 10 de abril y 29 de mayo de 2003, se hacen las siguientes manifestaciones:

«El ruido puede llegar a representar un factor psicopatógeno destacado en el seno de la sociedad y una fuente de permanente perturbación de la calidad de vida de los ciudadanos. Ciertos daños ambientales, en determinados casos de especial gravedad, aun cuando no pongan en peligro la salud de las personas, pueden atentar contra su derecho al respeto de su vida privada y familiar privándola del disfrute de su domicilio ... El Ayuntamiento actuó con pasividad pues se limitó a ordenar la incoación de expediente sancionador, pero sin acordar la adopción de la medida cautelar solicitada, recogida en la citada disposición autonómica (art. 20 de la Ley de Galicia 7/1997, de 11 de agosto, sobre protección contra la contaminación acústica) que es coherente con la competencia y responsabilidad de los Ayuntamientos en materia de medio ambiente ... Baste recordar que los apartados f) y h) del art. 25. (...) a general de los órganos municipales para la vigilancia del cumplimiento de las disposiciones sobre la materia (art.6) y, más particularmente, les reconoce funcio- 
nes de inspección sobre las actividades que vengan desarrollándose y potestad para adoptar medidas frente a las deficiencias comprobadas (arts. 36 y 37) ... El pleno y eficaz restablecimiento del derecho fundamental vulnerado (el derecho a la inviolabilidad del domicilio) exige ciertamente, para que su tutela no sea teórica, una indemnización por los daños y perjuicios sufridos a causa de dicha vulneración. Estos daños estarán representados por la imposibilidad de utilizar el domicilio habitual y la correlativa necesidad de buscar otro distinto para evitar la molestia; o, cuando se continúe en el propio, por la incomodidad o sufrimiento moral y físico experimentado en la vida personal».

En la sentencia de la Sección $5^{\text {a }}$ de la Sala Tercera del Tribunal Supremo de 23 de junio de 2003 se refleja lo siguiente:

«No existen potestades discrecionales en contra de la legalidad y la sentencia de instancia anula el acuerdo impugnado por una comunidad de propietarios porque comprueba que los ruidos producidos por las atracciones instaladas superan ampliamente los límites establecidos en la correspondiente Ordenanza y originan molestias insoportables a los vecinos ... Es el propio Ayuntamiento el que ha actuado ilegalmente al no ponderar debidamente la naturaleza de las actividades desarrolladas en un lugar inmediato a una zona residencial, reconociendo el propio Ayuntamiento que se causan molestias al vecindario, aunque se desprecia su importancia por limitarse a unos cuantos días del año».

Por último, la sentencia de la Sala Tercera del Tribunal Supremo de fecha 27 de abril de 2004, relativa a un recurso de casación promovido por un Ayuntamiento ejercitando los derechos fundamentales de sus vecinos afectados por el ruido producido por aviones en despegues y aterrizajes en el aeropuerto ubicado en el término municipal de dicha Entidad Local, se expresa en los siguientes términos:

«Nadie niega ahora que el ruido puede llegar a representar un factor psicopatógeno y puede ser una fuente de permanente perturbación en la calidad de vida, que atenta o pone en peligro la salud de las personas y la inviolabilidad del domicilio, pero siempre que los ruidos sean evitables e insoportables, calificativos que aquí no concurren, pues la evitabilidad debe producirse a tenor de las medidas previstas, pero aquí no aplicables ahora, y la insoportabilidad, como tal no consta en la sentencia recurrida".

\section{CONSIDERACIONES FINALES}

La promulgación de la nueva LR ha venido a paliar en buena medida la dispersidad normativa existente en materia de ordenación del ruido. Es el del ruido un fenómeno de actualidad como consecuencia de la creciente preocupación social sobre la calidad ambiental y la contaminación sono- 
ra. No puede desconocerse, en este sentido, que, según una encuesta publicada en algunos medios de comunicación, el 24 por 100 de la población se queja de vivir en una zona de saturación acústica, concurriendo además la circunstancia de que ciudades como Madrid son ciertamente ruidosas porque, con arreglo a dicha encuesta, el 28 por 100 de sus calles superan los 65 decibelios, que es el nivel máximo de ruido que establece la Organización Mundial de la Salud. De esta forma, la normativa sobre ruido y calidad ambiental y sobre protección contra las inmisiones acústicas es, a nuestro juicio, incuestionable y fundamental. Son de destacar, a este respecto, además de la citada LR de 2003, las Leyes de Galicia 7/1997, del País Vasco 3/1998 y de Cataluña 16/2002.

En la exposición de motivos de la propia LR se reconoce que «el ruido en su vertiente ambiental, no circunscrita a ámbitos específicos, como el laboral, sino en tanto que inmisión sonora presente en el habitat humano o en la naturaleza, no ha sido tradicionalmente objeto de atención preferente en la normativa protectora del medio ambiente. Tratamos del ruido en un sentido amplio - matiza la propia exposición de motivos-, y éste es el alcance de la Ley, comprensivo tanto del ruido propiamente dicho, perceptible en forma de sonido, como de las vibraciones: tanto uno como otras se incluyen en el concepto de "contaminación acústica" cuya prevención, vigilancia y reducción son objeto de esta Ley". Se concreta así en la LR el concepto de calidad ambiental acústica, especificando adecuadamente zonas o áreas acústicas -lo que requiere diferenciar reservas de sonidos de origen natural y las denominadas "zonas de servidumbre acústica»- y distinguiendo la acción preventiva de la acción correctora en materia de inmisiones sonoras.

Desde nuestro punto de vista, se hace preciso que las Corporaciones Locales regulen adecuadamente, tanto desde el punto de vista normativo como desde la perspectiva organizativa, los servicios administrativos en materia de contaminación acústica. Puede citarse así, como ejemplo reciente, el Decreto de la Alcaldía del Ayuntamiento de Madrid de 14 de junio de 2003 , en cuyo apartado decimocuarto, punto 1.3, se atribuye a la Concejalía de Gobierno de Medio Ambiente y Servicios a la Ciudad competencias en materia de calidad ambiental, tales como "formular y ejecutar la acción de control de la contaminación y corrección de los efectos producidos por las emisiones e inmisiones a la atmósfera por la producción de ruido".

Además del ulterior desarrollo normativo que requiere la $L R$, conforme al sistema de reparto competencial que en la misma se configura, resulta asimismo aconsejable el establecimiento de técnicas e instrumentos adecuados para la regulación de las distintas particularidades que presentan los variados sectores acústicamente contaminantes. Sirva de ejemplo, a 
este respecto, el Real Decreto 1257/2003, de 3 de octubre, por el que se regulan los procedimientos para la introducción de restricciones operativas relacionadas con el ruido en los aeropuertos, y que pretende establecer nuevos instrumentos para disminuir la contaminación acústica alrededor de los aeropuertos, mediante la trasposición de la Directiva 2002/30/CE del Parlamento europeo y del Consejo, de 26 de marzo de 2002, sobre la base de las siguientes medidas: determinar una estrategia integrada que garantice la compatibilidad del correcto funcionamiento y crecimiento de la aviación con la adecuada protección del medio ambiente; definir un marco equilibrado que asegure el desarrollo medioambiental sostenible de los aeropuertos; ofrecer a las compañías aereas un marco necesario para adaptar progresivamente sus flotas de aeronaves a los objetivos medioambientales y retirar gradualmente los aviones más ruidosos; y, en fin, integrar la gestión del ruido de los aeropuertos dentro de los objetivos de calidad acústica, conforme a los parámetros conceptuales definidos en la nueva LR.

Juntamente con las anteriores consideraciones normativas, debe destacarse la muy importante y significativa creación jurisprudencial que hasta la fecha - y según ha quedado expuesto en el presente trabajo- ha venido realizándose por parte de los Tribunales de Justicia, auténticos promotores de una ya consolidada doctrina en defensa y protección contra las perturbaciones ruidosas.

En términos jurídico-constitucionales, los artículos 15 y 18.2 de la CE otorgan plena cobertura normativa a la temática objeto de este estudio. Es de destacar, en esta línea de argumentación, que el derecho a disfrutar de un medio adecuado constituye un auténtico derecho subjetivo en la medida en que ciertamente se encuentra conectado con derechos fundamentales garantizados en dichos artículos, como son los derechos a la integridad física y moral, y a la intimidad personal y familiar en el ámbito domiciliario. Y se da la circunstancia, ciertamente relevante a los efectos de este trabajo, que el anterior posicionamiento se ha consolidado progresivamente en los últimos años. Prueba de ello son las sentencias del TEDH de fechas 9 de octubre de 1979, 21 de febrero de 1990, 9 de diciembre de 1994, 19 de febrero de 1998, 2 de octubre de 2001 y 16 de noviembre de 2004, así como las sentencias del TC 290/2000, de 30 de noviembre; 119/2001, de 24 de mayo; 16/2004, de 23 de febrero y 25/2004, de 26 de febrero.

$Y$ en los indicados términos constitucionales, el régimen sancionador en materia de contaminación acústica, a que aluden los artículos 28 y siguientes de la LR, es también ciertamente relevante. No se olvide, con respecto a este último particular, que del artículo 25.1 de la CE se infiere que nadie puede ser sancionado por acciones $u$ omisiones que, en el momento de producirse, no constituyan infracción administrativa, según la 
legislación vigente en ese preciso momento. Se constitucionaliza así el principio de legalidad en el ámbito del Derecho administrativo sancionador, extendiéndose de esta forma a dicho ámbito el principio de legalidad propio del orden penal, conforme ha declarado de manera uniforme la jurisprudencia contencioso-administrativa, entre otras, en las sentencias del Tribunal Supremo de fechas 14 de mayo de 1984 y 11 de marzo y 11 de noviembre de 2003. Desde este punto de vista, la última de las sentencias mencionadas declara que el referido artículo 25.1 recoge en nuestro sistema jurídico dos garantías esenciales: la llamada "garantía material», consistente en la predeterminación de las conductas, lo que ha sido ratificado en las sentencias del TC 75/1984 y 182/1990; y la denominada "garantía formal", que se concreta en la necesaria habilitación legal de la norma sancionadora, lo que ha sido reconocido en las sentencias del TC 77/1983, 42/1987, $101 / 1988,69 / 1989$ y $22 / 1990$.

Para concluir, debe ponerse especial énfasis en el hecho de que nadie duda hoy de la trascendencia social y jurídica de la que se ha venido en denominar "calidad acústica", de acuerdo con las Directivas sobre evaluación y gestión del ruido ambiental y sobre protección jurídica contra las inmisiones sonoras. La debida ordenación jurídica del fenómeno del ruido aconseja, en consecuencia, determinar y regular adecuadamente la exposición al mismo, poner a disposición de los ciudadanos la suficiente y precisa información sobre los efectos de la contaminación sonora, prevenir y reducir correctamente el propio ruido ambiental $y$, en definitiva, mantener y preservar la necesaria calidad del entorno acústico, con todo lo que ello comporta en defensa y protección de derechos fundamentales como la integridad física y moral y la intimidad personal y familiar en el ámbito domiciliario.

\section{BIBLIOGRAFÍA GENERAL}

\subsection{Libros}

Algarra Prats, E.: La defensa jur dico-civil frente a humos, olores, ruido y otras agresiones a la propiedad y a la Madrido,n1995.

Alonso García, C.: El r gimen jur dico de la contaminaci n atmosf rica $y$ ac sticaMadrid, 1995.

Betancor Rodríguez, A.: Instituciones de Derecho ambi AAadrid, 2001.

Evangelio LloRCA, R.: La acci n negatoria de inmisiones en el mbito de las relaciones de vecifuadada, 2000.

Fernández-Rodríguez, T. R.: El medio ambiente urbano y las vecindades industrial AAadrid, 1973. 
García SANZ, B. y GarRIDO, F.J.: La contaminaci n ac stica en nuestras ciu dades, Barcelona, 2003.

Gómez Puente, M.: La inactividad de la AdminisţPampłona, 2000.

GonzÁleZ-VARAs IBÁÑEZ, S.: Problemas procesales actuales de la jurisdic ci $n$ contencioso-administrą Gíanejo General del Poder Judicial, Madrid, 1993.

JoRdAno FragA, J.: La protecci n del derecho a un medio ambiente ade cuado, Barcelona, 1995.

Martín Mateo, R.: Tratado de Derecho Ambien,tMladrid, 1991.

Muñoz Sancho, M.: Anteproyecto de ordenanza sobre protecci $n$ del medio ambiente urbano contra la emisi n de, Mádrid, 1984.

Navarro Mendizábal, I.: Las inmisiones y molestias medioambientales. Tutela preventiva ,dMladirid, 1997.

Pérez Conejo, L.: La defensa judicial de los intereses ambientales: estudi espec fico de la legitimaci n difusa en el proceso contencioso-admi nistrati, ktalladolid, 2002.

Pérez Martos, J.: Ordenaci n jur dica del „IMládøid, 2002.

Pinedo Hay, J.: An lisis jur dico de la contaminaci n ac stica producida por las actividades de, Madibid, 2002.

Sosa Wagner, F.: - La lucha contra el rłléớn, 1990.

Las actividades molestas: en especial, Madrid,d1991.

VARIOS autores (dir. RuIz-Rıco RuIz, G.): La protecci n jurisdiccional del medio ambienteConsejo General del Poder Judicial, Madrid, 2001.

VARIOS AUTORES: Derecho ambientalRevista Jur dica General-Bolet n del Ilustre Colegio de Abogados de Mmont8, Madrid, 2001.

Varios autores (dir. Marín CAStÁn, F.): La tutela judicial frente a,I ruido Consejo General del Poder Judicial, Madrid, 2002.

Varios autores (dir. Piñar Mañas, J. L.): Desarrollo sostenible y protecci $n$ del medio ambientMladrid, 2002.

Varios autores (dir. Cosculluela Montaner, L.): Comentarios a la legis la ci n ambiental de la Comunidad de MąHlaidrid, 2003. 


\subsection{Art culos}

Álvarez-Cienfuegos SuÁreZ, J.M.: "La intimidad y el domicilio ante la contaminación acústica: nuevas perspectivas de los derechos fundamentales", en La Leyno 5437, Madrid, 2001.

BeAto Espejo, M.: - «El medio ambiente urbano y la convivencia ciudadana: el ruido por el consumo de bebidas en la vía pública», en Revista de Administraci n P bléḋ39, pág. 171, Madrid, 1996.

«El medio ambiente como bien jurídico protegido. El ruido como actividad molesta. Derecho a un ambiente silencioso y pacificador", en Revista de Derecho Urban suúms. 148 y 149, págs. 115 y 155 respectivamente, Madrid, 1996.

BLAsco ESTEVE, A.: "Idas y venidas en la lucha contra el ruido», en Revista de Administraci n $P$ blniC $\mathbf{k} 53$, pág. 267, Madrid, 2000.

Castelao Rodríguez, J.: "Ocio, pasividad municipal y orden público», en Revista de Estudios Lodaำ. Madrid, 2002.

Egea Fernández, J.: «Relevancia constitucional de las inmisiones por ruido ambiental procedente de una zona de ocio nocturno", en Derecho Privado y Constitucio \$15, pág. 69, Madrid, 2001.

FERnÁNDEZ AsIAIN, E.: "Las molestias y el derecho al silencio", en El pensa miento navarno 13, Pamplona, 1953.

GaRcía MACHO, R.: "El principio rector medio ambiente y la protección del ciudadano frente a los ruidos", en El Derecho Administrativo en el umbral del siglo XXI: homenaje al profesor Dr. D. Ram $n$ Mart $n$ Mateo, vol. III, pág. 3543, Valencia, 2000.

GARcía SAN JosÉ, D.: "Ruido nocturno e insomnio: los derechos a la vida privada y familiar y al respeto del domicilio frente al interés general de los vuelos de aviones durante la noche", en Revista Espa ola de Derecho Constitucioma6, pág. 239, Madrid, 2002.

Giménez OnTAÑón, V.: "La nueva Ley del Ruido", en La Leyno 6009, Madrid, 2004.

GonzÁlez PASTOR, C. P.: "La nueva Ley del Ruido: regulación administrativa y regulación penal, como delito contra el medio ambiente. Comentario a la sentencia del Tribunal Constitucional de 23 de febrero de 2004", en La Leyno 5982, Madrid, 2004.

López RAMÓN, F.: "La ordenación del ruido", en Revista de Administraci n P bli Cđํㅡ 157, pág. 27, Madrid, 2002. 
LLAMAS, E. y MAcíAs, A.: "Algunos paradigmas jurisprudenciales de la responsabilidad civil derivada del ruido», en Actualidad Cinñ¹44, pág. XLIV, Madrid, 1998.

MARTí MARTí, J.: — "La respuesta del derecho a las inmisiones sonoras", en La Leyno 5604, Madrid, 2002.

"Comentarios a la Ley 37/2003, del Ruido, y al nuevo marco de protección frente a la contaminación acústica», en La Leyno 5970, Madrid, 2004.

Martín-Retortillo Baquer, L.: — "La defensa frente al ruido ante el Tribunal Constitucional", en Revista de Administraci n P 舡1 15, pág. 205, Madrid, 1988.

"Los ruidos evitables", en Revista de Estudios de la Administraci $n$ Local y Auton mi đoa 238, pág. 1275, Madrid, 1988.

"El ruido en la reciente jurisprudencia», en Revista de Administraci $n$ P blic đo 125, pág. 319, Madrid, 1991.

"Medio ambiente sonoro", en Derecho del medio ambiente $y$ Administraci n laqpárg. 227, Madrid, 1996.

Pulido Quecedo, M.: "Sobre la defensa frente al ruido y el derecho a la intimidad domiciliaria", en Repertorio Aranzadi del Tribunal Constitucion 19 8, pág. 9, Pamplona, 2001.

Rodríguez CARBAJO, J. R.: "La contaminación acústica: análisis de la STS de 27 de abril de 2004", en Actualidad Administratriô3, pág. 1627, Madrid, 2004.

VACAs García-Alós, L.: «El Derecho de las inmisiones y la protección contra la contaminación acústica», en La Leyno 5886, Madrid, 2003.

VARIOS AUTORES: "Monografía de jurisprudencia sobre contaminación acústica», en La Ley no 6195, Madrid, 2005 